Rabaska

Revue d'ethnologie de l'Amérique française

\title{
Folklore et ethnologie de l'Amérique française
}

\section{Marcel Bénéteau}

Volume 8, 2010

URI : https://id.erudit.org/iderudit/045307ar

DOI : https://doi.org/10.7202/045307ar

Aller au sommaire du numéro

Éditeur(s)

Société québécoise d'ethnologie

ISSN

1703-7433 (imprimé)

1916-7350 (numérique)

Découvrir la revue

Citer ce document

Bénéteau, M. (2010). Folklore et ethnologie de l’Amérique française. Rabaska, 8 , 319-321. https://doi.org/10.7202/045307ar d'utilisation que vous pouvez consulter en ligne.

https://apropos.erudit.org/fr/usagers/politique-dutilisation/ 


\section{ONTARIO}

\section{Folklore et ethnologie de l'Amérique française}

Université de Sudbury

Sudbury (Ontario) P3E 2C6
Téléphone : (705) 673-5661

Télécopieur : (705) 673-4912

Courriel : mbeneteau@usudbury.ca

Toile : www.usudbury.com

\section{Enseignement}

Le département de Folklore et ethnologie de l'Amérique française maintient et élargit ses programmes de cours en direct et à distance. Les cours à distance demeurent une partie intégrale du programme et nous continuons de bénéficier des services de nos chargées de cours Diane Brazeau à Québec et Sophie Landry à Sudbury. Nos cours en direct sont fort appréciés par les étudiants de plusieurs disciplines; cette année, nous avons offert des cours sur les légendes, la chanson traditionnelle, la médecine populaire, les fêtes populaires, les rites de passage et, pour la première fois, le cours Folklore et pédagogie, cours qui souligne une approche pratique pour les étudiants en sciences de l'éducation cherchant à intégrer des éléments de folklore au programme des écoles françaises de l'Ontario.

Comme à chaque année, le prix Germain-Lemieux a été décerné à l'étudiant dont le rendement scolaire a été jugé le plus méritant ; pour l'année scolaire 2008-2009, le prix a été remis à Sylvie Rondeau au cours de la soirée de la remise des diplômes, le 8 octobre 2009.

Madame Lucie Beaupré quitte son poste de coordonnatrice du département de Folklore et d'ethnologie ; son aide et son appui ont été indispensables au développement de notre programme d'étude depuis les débuts du département. Madame Beaupré continuera son association à temps partiel avec le département, en particulier dans le domaine des cours à distance. Le rôle de coordonnateur sera assumé par le professeur Marcel Bénéteau.

\section{Activités}

La fête annuelle de la Sainte-Catherine, parrainée par le département de Folklore et le Centre franco-ontarien de folklore a pris de l'envergure cette année grâce à un partenariat avec l'équipe de la Nuit sur l'étang. Environ 125 personnes - étudiants, professeurs et membres de la communauté - ont participé à un café chantant suivi d'une danse « câllée » par notre invité spécial Louis Racine de Casselman. D'autres musiciens locaux ont contribué au succès de la soirée en interprétant des chansons du répertoire traditionnel, 
entre autres les Cokerels de Sudbury et une formation d'étudiants de l'école secondaire l'Horizon de Val-Caron. L'auteur du présent rapport a aussi présenté quelques chansons de son répertoire du sud-ouest ontarien.

\section{Recherche et diffusion}

Le département continue à participer à deux projets d'envergure : d'abord l'étude linguistique « Modéliser le changement : les voies du français », sous la direction de France Martineau de l'Université d'Ottawa. Le département maintient aussi sa participation comme partenaire ontarien de l'Encyclopédie du patrimoine culturel de l'Amérique française, sous la direction de Laurier Turgeon de l'Institut du patrimoine culturel de l'Université Laval. Nous avons coordonné la production de deux articles pour l'Encyclopédie : « Le Collège du Sacré-Cœur de Sudbury » et « Le Drapeau franco-ontarien »; plusieurs autres articles sont en voie de développement. Le département de Folklore et ethnologie continue aussi sa participation à deux projets basés à Sudbury : l'Inventaire du patrimoine franco-ontarien, activité parrainée par le Centre franco-ontarien de folklore et le Trésor de la langue française en Ontario à l'Université Laurentienne.

Le département participe également à un protocole d'entente signé par l'Université de Sudbury et la Nation métisse de l'Ontario afin de développer des projets de recherche qui reflètent les intérêts des deux organismes. Les membres de la NMO ont identifié un besoin particulier pour la recherche dans les domaines de langue, culture et identité ; le département participe activement à la création de projets qui pourront développer cet aspect important de la culture franco-ontarienne.

Le coordonnateur du département a aussi présenté les résultats de ses recherches auprès de plusieurs groupes et organismes, entre autres à la Société historique du Nouvel-Ontario, le Groupe de recherche en études acadiennes à l'Université Sainte-Anne et le festival de livres « Bookfest » Windsor.

Nous continuons le catalogage des collections des Archives de folklore de l'Université de Sudbury. Grâce à l'aide de l'étudiante Sonja Sweet, nous avons terminé le volet des chansons traditionnelles, soit 7376 versions de 733 chansons types identifiées d'après les catégories du Catalogue de la chanson folklorique française de Conrad Laforte.

L'année se termine avec l'annonce du rapatriement du Centre francoontarien de folklore à l'Université de Sudbury. Cet événement historique présente de nombreuses opportunités à la fois pour le Centre et pour le département de Folklore. Pour nos étudiants, la présence du CFOF sur campus met en disponibilité ses archives de patrimoine oral qui viendront enrichir leurs cours et approfondir leur appréciation de la culture traditionnelle de 
l'Ontario français. Les étudiants pourront aussi participer aux expositions et aux événements culturels et communautaires que le Centre organise pour diffuser et mettre en valeur le patrimoine franco-ontarien. La présence sous un seul toit des ressources du CFOF - archives, bibliothèque spécialisée, collection d'objets patrimoniaux - et des archives du département de Folklore crée d'un seul coup un centre de ressources qui s'avère fort intéressant pour les chercheurs dans plusieurs domaines, ainsi que pour tous les membres de la communauté francophone.

Marcel BÉNÉTEAU 